\title{
A detailed model for defect concentration and dopant activation in GaAs
}

\author{
DEEPAK* and N LAKSHMINARAYANA \\ Department of Materials and Metallurgical Engineering, Indian Institute of Technology, Kanpur 208 016, India
}

MS received 7 November 2000

\begin{abstract}
Defects in semi-insulating (SI) GaAs are especially critical in determining the properties of devices in which dopants are introduced by ion-implantation. The defects in GaAs are native to the material and their concentrations are subsequently modified after ion-implantation and annealing. In this work, we have extended the existing models in the literature by incorporating a large set of defects and using the most recent values for formation energies of these defects. The model includes eight types of point defects, the vacancy of Ga and As, their antisites and interstitials of $\mathrm{Ga}$ and $\mathrm{As}$ on both sub-lattices, along with carbon related defects always present in SI-GaAs. We have also included $\mathrm{Si}$ and related defects when this element is implanted as an $n$-type dopant. All these defects are considered in several charge states allowed by their stability conditions. The model assumes thermodynamic equilibrium between the point defects at an anneal temperature. Then the GaAs wafer is quenched so that the number of defects remain the same as those at the anneal temperature, but redistribution of charges occurs in various charge states. We find that the defect concentrations are extremely sensitive to the crystal stoichiometry, and good agreement with experimental data is shown. However, when we calculate the dopant activation in implanted GaAs, the quantitative agreement with experiments is not adequate. This discrepancy is explained on the basis of available formation energies for the defects.
\end{abstract}

Keywords. Semi-insulating; GaAs; dopant activation; defects.

\section{Introduction}

A semi-insulating (SI) GaAs crystal is grown by deliberately keeping it As rich to create preponderance of As antisites $\left(\mathrm{As}_{\mathrm{Ga}}\right)$. Since coupling power through a graphite susceptor melts GaAs during growth, typically the concentration of carbon, which is a $p$-type dopant in GaAs, is $10^{15} \mathrm{~cm}^{-3}$ (Holmes et al 1982; Orito et al 1990). Thus, $\mathrm{As}_{\mathrm{Ga}}$, which has an energy level in the middle of the band gap of GaAs, is kept at least at $10^{16} \mathrm{~cm}^{-3}$ (Holmes et al 1982; Orito et al 1990) so that the material behaves as a semi-insulating substrate.

Because the crystal is As rich, the defect concentrations in SI-GaAs are high. Ultimately, when dopants such as Si are incorporated, the 'activation' of these dopants can be severely limited by these defects, adversely affecting the performance of an implanted GaAs device. Therefore, it is necessary to control the crystal stoichiometry and accordingly the defects in the crystal.

In this paper, we present a point defect based thermodynamic model to compute the defect concentrations, specifically as a function of crystal stoichiometry, and then for cases where $\mathrm{Si}$ is implanted.

Closely related to the model presented here are models given by Kengkan and Morrow (1995), Kengkan et al (1994) and Ichimura et al (1993). The models defer in the

\footnotetext{
*Author for correspondence
}

number of defects considered and the source of formation energies used to compute the defect concentrations. Probably the model presented by Ichimura et al (1993) is most comprehensive. They have considered both capless anneal and anneal with a cap layer. However, the defect formation energies are computed by open cavity approach of Van Vechten (1975). Since then, much more comprehensive calculations have been done and, hence, the defect states also need to be modified.

In this work, we have confined ourselves primarily to the single largest source (Northrup and Zhang 1993) for defect states and formation energies.

\section{Defect thermodynamic model}

The point defects in GaAs in their lowest charged states are (Northrup and Zhang 1993): $\mathrm{V}_{\mathrm{Ga}}^{0}, \mathrm{~V}_{\mathrm{As}}^{+}, \mathrm{Ga}_{\mathrm{I} 1}^{+}, \mathrm{Ga}_{\mathrm{I} 2}^{+}$, $\mathrm{As}_{\mathrm{I} 1}^{0}, \mathrm{As}_{\mathrm{I} 2}^{0}, \mathrm{As}_{\mathrm{Ga}}^{0}$ and $\mathrm{Ga}_{\mathrm{As}}^{0}$. The equilibrium between these defects is defined by the reactions given below, where the symbol V denotes a vacancy and we write the defect reactions with subscripts and superscripts identifying the site and the charge state, respectively.
I. $\mathrm{Ga}_{\mathrm{Ga}}=\mathrm{V}_{\mathrm{Ga}}^{0}+\mathrm{Ga}_{\mathrm{I} 1}^{+}+e$,
II. $\mathrm{Ga}_{\mathrm{Ga}}=\mathrm{V}_{\mathrm{Ga}}^{0}+\mathrm{Ga}_{\mathrm{I} 2}^{+}+e$,
III. $\mathrm{As}_{\mathrm{As}}=\mathrm{V}_{\mathrm{As}}^{+}+\mathrm{As}_{\mathrm{I} 1}^{0}+e$,
IV. $\mathrm{As}_{\mathrm{As}}=\mathrm{V}_{\mathrm{As}}^{+}+\mathrm{As}_{\mathrm{I} 2}^{0}+e$, 
V. $0=\mathrm{V}_{\mathrm{Ga}}^{0}+\mathrm{V}_{\mathrm{As}}^{+}+e$,

VI. $\mathrm{Ga}_{\mathrm{Ga}}+\mathrm{V}_{\mathrm{As}}^{+}+e=\mathrm{Ga}_{\mathrm{As}}^{0}+\mathrm{V}_{\mathrm{Ga}}^{0}$ and

VII. $\mathrm{As}_{\mathrm{As}}+\mathrm{V}_{\mathrm{Ga}}^{0}=\mathrm{As}_{\mathrm{Ga}}^{0}+\mathrm{V}_{\mathrm{As}}^{+}+e$,

where interstitial site I1 (I2) has 4 arsenic (gallium) neighbours.

The equilibrium, for example, for reaction VII, is written as

$$
\frac{\left[\mathrm{V}_{\mathrm{As}}^{+}\right]\left[\mathrm{As}_{\mathrm{Ga}}^{0}\right]}{\left[\mathrm{V}_{\mathrm{Ga}}^{0}\right]}=\exp \left[-\left(\frac{g_{\mathrm{As}}^{f}+g_{\mathrm{Ga}}^{f}+E_{\mathrm{Fs}}-g_{\mathrm{V}_{\mathrm{Ga}}^{0}}^{f}}{k T}\right)\right] .
$$

The quantity ' $g$ ' in (1) is the Gibb's free energy of formation of a defect. The quantity in the square brackets is the defect concentration in $\mathrm{cm}^{-3}$ divided by the total number of possible sites in $\mathrm{cm}^{-3}$. The defect equilibrium for other six reactions is written similarly.

The higher charged states for the acceptor and donor defects, represented by a dot, are computed according to:

and

$$
\left[\bullet^{z-}\right]=\left[\bullet^{(z-1)-}\right] \exp \left(\frac{E_{\mathrm{F}}-E_{\boldsymbol{.}^{-}}^{\mathrm{a}}}{k T}\right)
$$

$$
\left[\bullet^{z+}\right]=\left[\bullet^{(z-1)+}\right] \exp \left(\frac{E_{\bullet^{z+}}^{\mathrm{d}}-E_{\mathrm{F}}}{k T}\right),
$$

respectively. The energies appearing in the parenthesis are Fermi energy $\left(E_{\mathrm{F}}\right)$, and ionization energies of acceptors $\left(E^{\mathrm{a}}\right)$ and donors $\left(E^{\mathrm{d}}\right)$.

Normally, semi-insulating GaAs also contains carbon impurity. If total carbon concentration is $\mathrm{C}_{\mathrm{T}}$, distributed between $\mathrm{C}_{\mathrm{I}}^{0}, \mathrm{C}_{\mathrm{I}}^{1+}, \mathrm{C}_{\mathrm{I}}^{2+}$ (in absence of specific information, only $\mathrm{I} 1$ is considered), $\mathrm{C}_{\mathrm{As}}^{1-}$ and $\mathrm{C}_{\mathrm{Ga}}^{1+}$, then

$$
\mathrm{C}_{\mathrm{T}} / \beta=\left[\mathrm{C}_{\mathrm{I}}^{0}\right]+\left[\mathrm{C}_{\mathrm{I}}^{1+}\right]+\left[\mathrm{C}_{\mathrm{I}}^{2+}\right]+\left[\mathrm{C}_{\mathrm{As}}^{1-}\right]+\left[\mathrm{C}_{\mathrm{Ga}}^{1+}\right],
$$

where $\beta$ is number of $\mathrm{Ga}$ or As sites per unit volume. Also, the two equilibrium involving carbon defects are

VIII. $\mathrm{C}_{\mathrm{I}}^{0}+\mathrm{V}_{\mathrm{Ga}}^{0}=\mathrm{C}_{\mathrm{Ga}}^{1+}+e$,

IX. $\mathrm{C}_{\mathrm{I}}^{0}+\mathrm{V}_{\mathrm{As}}^{+}+2 e=\mathrm{C}_{\mathrm{As}}^{1-}$,

and the higher charge states of carbon interstitials are computed using (2).

Similarly, when $\mathrm{Si}$ is added in amount $\mathrm{Si}_{\mathrm{T}}$, equilibrium

X. $\mathrm{Si}_{\mathrm{I}}^{0}+\mathrm{V}_{\mathrm{Ga}}^{0}=\mathrm{Si}_{\mathrm{Ga}}^{0}$,

XI. $\mathrm{Si}_{\mathrm{I}}^{0}+\mathrm{V}_{\mathrm{As}}^{+}+e=\mathrm{Si}_{\mathrm{As}}^{0}$, provides two equilibrium equations and the higher charge states (Northrup and Zhang 1993), $\mathrm{Si}_{\mathrm{As}}^{1-}$ and $\mathrm{Si}_{\mathrm{Ga}}^{1+}$, satisfy (2). Also, total Si concentration is constrained by a relation similar to (3).

Furthermore, if $\alpha$ is the ratio of number of As and Ga atoms in the material, then the mass balance is expressed as

$$
\begin{aligned}
& 1+\sum_{z}\left[\mathrm{As}_{\mathrm{Ga}}^{z}\right]-\sum_{z}\left[\mathrm{Ga}_{\mathrm{As}}^{z}\right]-\sum_{z}\left[\mathrm{~V}_{\mathrm{As}}^{z}\right]+\sum_{z}\left[\mathrm{As}_{\mathrm{I} 1}^{z}\right] \\
& +\sum_{z}\left[\mathrm{As}_{\mathrm{I} 2}^{z}\right]-\sum_{z}\left[\mathrm{C}_{\mathrm{As}}^{z}\right]-\sum_{z}\left[\mathrm{Si}_{\mathrm{As}}^{z}\right] \\
& 1-\sum_{z}\left[\mathrm{As}_{\mathrm{Ga}}^{z}\right]+\sum_{z}\left[\mathrm{Ga}_{\mathrm{As}}^{z}\right]-\sum_{z}\left[\mathrm{~V}_{\mathrm{Ga}}^{z}\right]+\sum_{z}\left[\mathrm{Ga}_{\mathrm{I} 1}^{z}\right] \\
& +\sum_{z}\left[\mathrm{Ga}_{\mathrm{I} 2}^{z}\right]-\sum_{z}\left[\mathrm{C}_{\mathrm{Ga}}^{z}\right]-\sum_{z}\left[\mathrm{Si}_{\mathrm{Ga}}^{z}\right]
\end{aligned}
$$

whereas the charge balance is quantitatively written as

$$
\begin{aligned}
& \left(\frac{n_{\mathrm{i}}^{2}}{n \beta}-\frac{n}{\beta}\right)+\sum_{z} z\left[\mathrm{~V}_{\mathrm{Ga}}^{z}\right]+\sum_{z} z\left[\mathrm{~V}_{\mathrm{As}}^{z}\right]+\sum_{z} z\left[\mathrm{As}_{\mathrm{Ga}}^{z}\right] \\
& +\sum_{z} z\left[\mathrm{Ga}_{\mathrm{As}}^{z}\right]+\sum_{z} z\left[\mathrm{As}_{\mathrm{I} 1}^{z}\right]+\sum_{z} z\left[\mathrm{As}_{\mathrm{I} 2}^{z}\right] \\
& +\sum_{z} z\left[\mathrm{Ga}_{\mathrm{I} 1}^{z}\right]+\sum_{z} z\left[\mathrm{Ga}_{\mathrm{I} 2}^{z}\right]+\sum_{z} z\left[\mathrm{C}_{\mathrm{Ga}}^{z}\right]+\sum_{z} z\left[\mathrm{C}_{\mathrm{As}}^{z}\right] \\
& +\sum_{z} z\left[\mathrm{C}_{\mathrm{I}}^{z}\right]+\sum_{z} z\left[\mathrm{Si}_{\mathrm{Ga}}^{z}\right]+\sum_{z} z\left[\mathrm{Si}_{\mathrm{As}}^{z}\right]+\sum_{z} z\left[\mathrm{Si}_{\mathrm{I}}^{z}\right]=0,
\end{aligned}
$$

where $n$ is the electron density, and $n_{\mathrm{i}}$ the intrinsic electron concentration.

Additional equations that completely describe the physics include

$$
n=N_{\mathrm{c}} \exp \left(\frac{E_{\mathrm{F}}-E_{\mathrm{c}}}{k T}\right),
$$

where $E_{\mathrm{c}}$ is conduction band minima (measured from valence band maxima) and $N_{\mathrm{c}}$ the density of states in conduction band.

The equations above are for the high temperature process encountered during the crystal growth, or in a more practical situation, during annealing. Following the high temperature step, the material is then cooled. With the diffusion of atomic species greatly reduced at low temperatures, the defects are assumed to 'freeze' in number at a level corresponding to the anneal temperature. However, the electronic processes being fast, charge redistribution establishes a new equilibrium at low temperature. In computing the redistribution of charges, the total quantity of a defect is kept constant at its value at anneal temperature and, again, the thermal equilibrium and charge balance equations are solved at $300 \mathrm{~K}$.

In practice, a GaAs boule or a wafer may be cooled slowly, rather than by quenching, and hence the concen- 
tration of defects may change dynamically during cooling until the atomic mobility becomes too small. Nonetheless, at low temperatures such as $300 \mathrm{~K}$, the defect concentrations correspond to a much higher temperature value at which atomic mobility is large. Such temperatures are usually in excess of $1000 \mathrm{~K}$ (for example, diffusion coefficient of $\mathrm{Si}$ in $\mathrm{GaAs}$ in $\mathrm{cm}^{2} / \mathrm{s}$ is $3 \times 10^{-9} \exp (-1.6 \mathrm{eV} / k T)$ (Deal et al 1989), which at $1000 \mathrm{~K}$ is only $2.6 \times 10^{-17}$ and at $800 \mathrm{~K}$ it is $2.5 \times 10^{-19} \mathrm{~cm}^{2} / \mathrm{s}$ ). In the model presented here, since the defect dynamics is not included, we have assumed defect concentrations to correspond to a temperature in excess of $1000 \mathrm{~K}$.

\section{Results and discussion}

The formation energy data for the defects considered here is listed in table 1. First we compute the effect of crystal stoichiometry on defect concentrations for an as-grown crystal. In computed results presented in figures 1 and 2, $\mathrm{C}$ contamination is $1 \times 10^{15} \mathrm{~cm}^{-3}$ and the crystal is annealed at $1200 \mathrm{~K}$ and $1473 \mathrm{~K}$, respectively. In both cases, the defect concentrations suffer a sharp transition near stoichiometric GaAs composition. This result is consistent with the experimental observation of Holmes et al (1982).

Although, we may know the melt stoichiometry from the growth conditions, the crystal stoichiometry is different from that of the melt. Furthermore, typically the suppliers of the wafers specify the EL2 concentration and not the crystal stoichiometry. Thus we first plot defect concentrations as a function of As/Ga ratio, so that knowing the EL2 (related to $\mathrm{As}_{\mathrm{Ga}}$ ) concentration, we can determine the corresponding As/Ga ratio for the crystal.

Table 1. Defect energies (Northrup and Zhang 1993). $E_{\mathrm{G}}$ is band gap of GaAs.

\begin{tabular}{lclc}
\hline Defect & $\begin{array}{c}\text { Formation } \\
\text { energy }(\mathrm{eV})\end{array}$ & \multicolumn{1}{c}{ Defect } & $\begin{array}{c}\text { Ionization } \\
\text { energy }(\mathrm{eV})\end{array}$ \\
\hline $\mathrm{V}_{\mathrm{Ga}}^{0}$ & $4 \cdot 55$ & $\mathrm{~V}_{\mathrm{Ga}}(0 /-1)$ & $0 \cdot 19$ \\
$\mathrm{~V}_{\mathrm{As}}^{+}$ & $2 \cdot 97$ & $\mathrm{~V}_{\mathrm{Ga}}(-1 /-2)$ & $0 \cdot 20$ \\
$\mathrm{Ga}_{\mathrm{I} 1}^{+}$ & $2 \cdot 14$ & $\mathrm{~V}_{\mathrm{Ga}}(-2 /-3)$ & $0 \cdot 32$ \\
$\mathrm{Ga}_{\mathrm{I} 2}^{+}$ & $2 \cdot 00$ & $\mathrm{Ga}_{\mathrm{I} 1}(+1 /+2)$ & $0 \cdot 55$ \\
$\mathrm{As}_{\mathrm{I1}}^{0}$ & $6 \cdot 14$ & $\mathrm{Ga}_{\mathrm{I} 1}(+2 /+3)$ & $0 \cdot 52$ \\
$\mathrm{As}_{\mathrm{I} 2}^{0}$ & $6 \cdot 14$ & $\mathrm{As}_{\mathrm{I} 1}(0 /+1)$ & $1 \cdot 05$ \\
$\mathrm{As}_{\mathrm{Ga}}^{0}$ & $2 \cdot 50$ & $\mathrm{As}_{\mathrm{I} 1}(+1 /+2)$ & $0 \cdot 96$ \\
$\mathrm{Ga}_{\mathrm{As}}^{0}$ & $2 \cdot 74$ & $\mathrm{As}_{\mathrm{I} 1}(+2 /+3)$ & $0 \cdot 98$ \\
$\mathrm{C}_{\mathrm{As}}^{1-}$ & $1 \cdot 04$ & $\mathrm{As}_{\mathrm{Ga}}(0 /+1)$ & $0 \cdot 76$ \\
$\mathrm{C}_{\mathrm{Ga}}^{1+}$ & $1 \cdot 45$ & $\mathrm{As}_{\mathrm{Ga}}(+1 /+2)$ & $0 \cdot 61$ \\
$\mathrm{C}_{\mathrm{I} 1}^{0}$ & $4 \cdot 02$ & $\mathrm{Ga}_{\mathrm{As}}(0 /-1)$ & $0 \cdot 55$ \\
$\mathrm{Si}_{\mathrm{Ga}}^{0}$ & $E_{\mathrm{G}}-0 \cdot 004$ & $\mathrm{Ga}_{\mathrm{As}}(-1 /-2)$ & $0 \cdot 21$ \\
$\mathrm{Si}_{\mathrm{As}}^{0}$ & $1 \cdot 265$ & $\mathrm{C}_{\mathrm{I} 1}(0 /+1)$ & $1 \cdot 10$ \\
$\mathrm{Si}_{\mathrm{I}}^{0}$ & $3 \cdot 00$ & $\mathrm{C}_{\mathrm{I} 1}(+1 /+2)$ & $1 \cdot 12$ \\
& & $\mathrm{Si}_{\mathrm{Ga}}(0 /+1)$ & $E_{\mathrm{G}}-0 \cdot 006$ \\
& & $\mathrm{Si}_{\mathrm{As}}(0 /-1)$ & $0 \cdot 035$ \\
\hline
\end{tabular}

Typically, the As antisite concentration in the substrate material is $\sim 10^{16} \mathrm{~cm}^{-3}$. At both temperatures, we find for $\mathrm{As}_{\mathrm{Ga}}=1.15 \times 10^{16} \mathrm{~cm}^{-3}, \alpha$ is 1.000001 . However, a sharp transition in concentrations around $\alpha=1$ means defect concentrations will strongly depend on the stoichiometry. Comparatively, the EL2 concentration is not so sensitive to the annealing temperature, as seen from figures 1 and 2. Since an arsenic antisite concentration on the order of $10^{16} \mathrm{~cm}^{-3}$ requires a crystal stoichiometry that lies in the sharp transition region, an accurate value of $\alpha$ is needed for comparison with experiments. Unfortunately, however, the crystal stoichiometry quantity is not measured easily or reported extensively in the literature. Nonetheless, it is clear, unless the supplier of wafer controls the crystal stoichiometry tightly, the defect con-

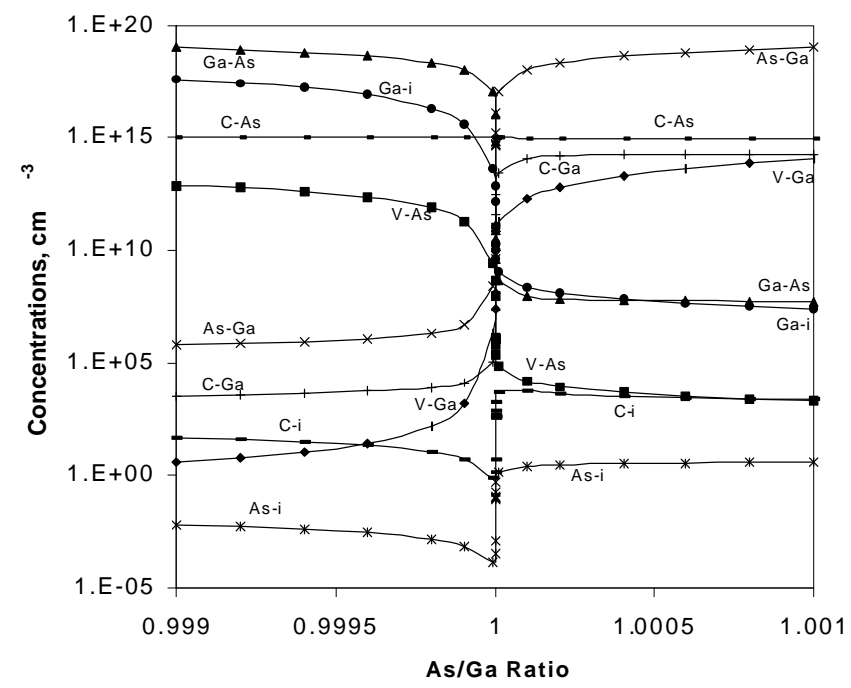

Figure 1. Defect concentrations in as-grown GaAs annealed at $1200 \mathrm{~K}$.

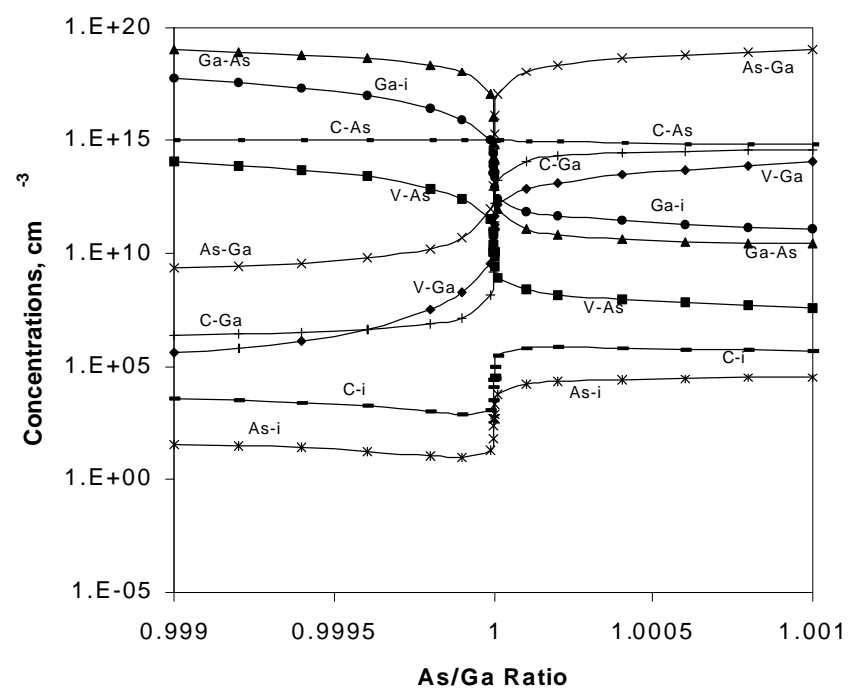

Figure 2. Defect concentrations in as-grown GaAs annealed at $1473 \mathrm{~K}$. 
centration will vary, seriously affecting the device performance through dopant activation (Deepak et al 2001). We find that this aspect so far has not been addressed sufficiently for cases where annealing is under the constraint of invariant stoichiometry.

Also, from a practical viewpoint, a sharp sensitivity of defect concentrations near $\alpha=1$ implies that As loss during anneal can convert a surface layer to $p$-type, resulting in a spurious junction in the device.

Furthermore, in the past, in materials that we have used with EL2 concentration approximately at $10^{16} \mathrm{~cm}^{-3}$, we found that the carrier concentration measurement was clustered around $10^{7} \mathrm{~cm}^{-3}$ and, for example, also see Holmes et al (1982). In comparison, computed intrinsic electron concentration at $300 \mathrm{~K}$ is $2.27 \times 10^{6} \mathrm{~cm}^{-3}$. For a similar EL2 level, which in calculation corresponds to As/Ga ratio of 1.000001 , the total carrier concentration is computed as $6 \times 10^{6} \mathrm{~cm}^{-3}$, a value in close agreement with the measurement. Thus, for the purpose of evaluating dopant activation, we consider a wafer with As/Ga ratio 1.000001. However, it may be noted that based on the measurement of melt concentration corresponding to the sharp transition region by Holmes et al (1982), and then converting that melt stoichiometry to $\alpha$ using a chart provided by Ichimura et al (1993), we find that value of $\alpha$ should be greater than 1.000001. But with an enormous spread in data correlating the melt and crystal stoichiometry, and for the limited purpose of evaluating dopant activation, we accept $\alpha$ as 1.000001 .

We are interested in concentration of defects in the regions where Si has been implanted. So we consider a substrate that has As/Ga ratio as 1.000001. Then we implant $\mathrm{Si}$ and compute defect concentrations after an anneal at $1200 \mathrm{~K}$. First we calculate defect concentrations for $\mathrm{Si}_{\mathrm{T}}=10^{17} \mathrm{~cm}^{-3}$. Various concentrations for $\mathrm{V}_{\mathrm{Ga}}, \mathrm{V}_{\mathrm{As}}$, $\mathrm{Ga}_{\mathrm{As}}, \mathrm{As}_{\mathrm{Ga}}, \mathrm{Ga}_{\mathrm{I} 1}, \mathrm{Ga}_{\mathrm{I} 2}, \mathrm{C}_{\mathrm{As}}, \mathrm{C}_{\mathrm{Ga}}, \mathrm{Si}_{\mathrm{As}}, \quad \mathrm{Si}_{\mathrm{Ga}}, \mathrm{Si}_{\mathrm{I}}$ are $3.5 \times 10^{8}, 3.8 \times 10^{7}, 1.1 \times 10^{14}, 4.73 \times 10^{11}, 1.3 \times 10^{11}$, $4.57 \times 10^{11}, 9.96 \times 10^{14}, 1.11 \times 10^{8}, 3.8 \times 10^{16}, 6 \cdot 1 \times 10^{16}$, $1.4 \times 10^{7} \mathrm{~cm}^{-3}$, respectively. It is necessary to know these concentrations in order to also simulate the electrical response of a Si implanted device. Often indeed both carbon and silicon dopants are accounted for during electrical simulations (for example, Deepak et al 2001). All of $\mathrm{C}$ is assumed to be on As site, which is consistent with our calculations here. However, in the case of $\mathrm{Si}$, apart from that on Ga site, a significant amount of Si resides on As site. This seriously affects the dopant activation, defined as ratio of electron concentration to total Si present in the wafer. Unfortunately, in absence of detailed information, it is common to carry out device simulations in which effective $\mathrm{Si}$ concentration available as dopant is taken to be total $\mathrm{Si}$ reduced by a factor corresponding to the dopant activation. Often, this factor is treated a constant, which clearly is incorrect as this 'activation' will be $\mathrm{Si}_{\mathrm{T}}$ dependent. Furthermore, besides EL2 no other defects are included in device simulations. But the prediction of device characteristics in electrical simulations could improve with inclusion of next most important defect, the gallium vacancy, with three relatively deep acceptor levels.

We have also investigated the effect of Si addition on electron concentration, after annealing at $1200 \mathrm{~K}$ (figure 3 ). The straight line gives the electron concentration if all $\mathrm{Si}$ occupied Ga site. That is, activation efficiency of one. The two dashed curves are taken from Kengkan et al (1994). They represent the spread in measured data. In our calculations, squares in figure 3 , the activation efficiency does increase with increasing concentration of $\mathrm{Si}$, as expected. The quantitative agreement is good up to $\sim 10^{17} \mathrm{~cm}^{-3} \mathrm{Si}$. But beyond this concentration, we compute much more compensation than measured. Measured value of activation efficiency also shows a plateau in electron concentration (Kengkan et al 1994), as does results in figure 3. However, measurements show this plateau beyond $10^{18} \mathrm{~cm}^{-3} \mathrm{Si}$ and peak value for ' $n$ ' is also in that order of concentration.

The parameters for our model are As/Ga ratio, and the defect formation energies. As/Ga ratio is the most critical parameter, as demonstrated in figures 1 and 2. But also, because the concentration of defects follow an exponential dependence in formation energy, an error of $0.01 \mathrm{eV}$ in formation energy introduces $38 \%$ error in defect concentration at $300 \mathrm{~K}$ and $12 \%$ at $1000 \mathrm{~K}$. Thus, the source of data for formation energy needs to be discussed.

The defect energies have been computed (Northrup and Zhang 1993) as the total internal energy of formation of the defect. Thus, the entropic contributions to the Gibb's free energy have been neglected. The computed values for Gibb's free energy of a defect formation, therefore, may be a good approximation at $0 \mathrm{~K}$ or a low temperature, but certainly incorrect at elevated temperatures that are encountered during annealing or crystal growth. This error is as great as few $k T$. Therefore, since the computed

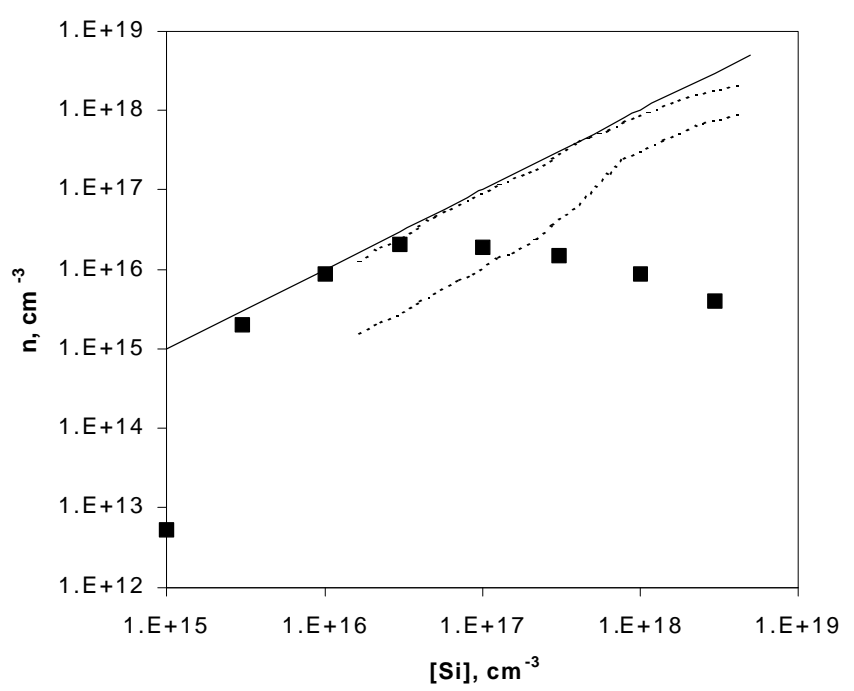

Figure 3. Activation efficiency of Si impurity after annealing at $1200 \mathrm{~K}$; As/Ga ratio is 1.000001 . 
data is applicable at $0 \mathrm{~K}$, quantitative differences reported in figure 3 are not surprising.

\section{Conclusions}

We have presented a thermodynamic model for point defects in GaAs, which also includes $\mathrm{C}$ and $\mathrm{Si}$ impurities. The calculations for defect and electron concentrations were compared with the measured data. The crystal stoichiometry is shown to have most significant effect on defect concentrations. But, because the substrate manufacturers usually specify EL2 concentration, rather than crystal stoichiometry, a correlation between the two needs to be measured so that $\alpha$ can be calibrated. A correlation between EL2 and melt stoichiometry is available in literature. Thus, knowing a relationship between melt and corresponding crystal composition is sufficient. Such a measurement is reported by Ichimura et al (1993). However, there is too much scatter in the data.

We have also shown a qualitative agreement with measurements for activation efficiency. Reason for quantitative variance with measurements in some cases, both when $\mathrm{Si}$ is present and in SI wafer, is due to inadequate information on formation energies of defects. It would be possible for us to modify these energies, especially those associated with Si to provide a match with experimental data. But such manipulation will not be a general one. And given that the purpose of simulation is to provide predictive capability over a wide range, arbitrary manipulation cannot achieve this goal. Therefore, we suggest that instead of ad-hoc modification of formation energy parameter, as has been done in some previously published literature (for example, Ichimura et al 1993), there is a need for systematic manipulation of formation energy. We are currently focussing on artificial intelligence techniques to together vary all formation energies within a justified range in order to select a set which ensures a match between calculated and experimental results.

\section{References}

Deal M D, Hansen S E and Sigmon T W 1989 IEEE Trans. Computer Aided Design $\mathbf{8} 939$

Deepak, Blakey P A and Johnson K 2001 J. Electronic Mater. 3070

Holmes D E, Chen R T, Elliot K R, Kirkpatrick C G and Yu P W 1982 IEEE Trans. Microwave Theory and Tech. 30949

Ichimura M, Usami A and Wada T 1993 Modelling Simul. Mater. Sci. Eng. 1529

Kengkan P and Morrow R A 1995 J. Sci. Soc. Thailand 21 215

Kengkan P, Mealing A and Morrow R A 1994 Phys. Rev. B49 16309

Northrup J E and Zhang S B 1993 Phys. Rev. B47 6791

Orito F, Watanabe K, Yamada Y, Yamamoto O and Yajima F 1990 GaAs IC symposium (IEEE) p. 321

Van Vechten J A 1975 J. Electrochem. Soc. 122 419, 423 